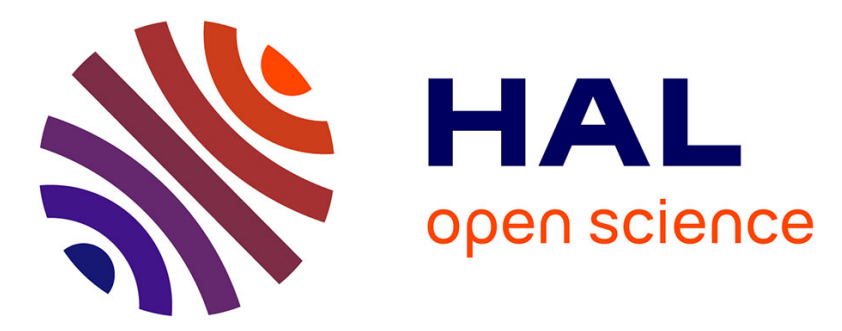

\title{
Peritoneal Wash Cytology in Gastric Carcinoma. Prognostic Significance and Therapeutic Consequences
}

M. La Torre, M. Ferri, M.R. Giovagnoli, N. Sforza, G. Cosenza, E. Giarnieri, V. Ziparo

\section{- To cite this version:}

M. La Torre, M. Ferri, M.R. Giovagnoli, N. Sforza, G. Cosenza, et al.. Peritoneal Wash Cytology in Gastric Carcinoma. Prognostic Significance and Therapeutic Consequences. EJSO - European Journal of Surgical Oncology, 2010, 36 (10), pp.982. 10.1016/j.ejso.2010.06.007 • hal-00625569

\section{HAL Id: hal-00625569 https://hal.science/hal-00625569}

Submitted on 22 Sep 2011

HAL is a multi-disciplinary open access archive for the deposit and dissemination of scientific research documents, whether they are published or not. The documents may come from teaching and research institutions in France or abroad, or from public or private research centers.
L'archive ouverte pluridisciplinaire HAL, est destinée au dépôt et à la diffusion de documents scientifiques de niveau recherche, publiés ou non, émanant des établissements d'enseignement et de recherche français ou étrangers, des laboratoires publics ou privés. 


\section{Accepted Manuscript}

Title: Peritoneal Wash Cytology in Gastric Carcinoma. Prognostic Significance and Therapeutic Consequences

Authors: M. La Torre, M. Ferri, M.R. Giovagnoli, N. Sforza, G. Cosenza, E. Giarnieri, V. Ziparo

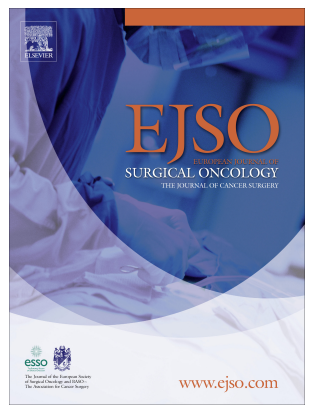

PII: S0748-7983(10)00183-6

DOI: 10.1016/j.ejso.2010.06.007

Reference: YEJSO 2995

To appear in: European Journal of Surgical Oncology

Received Date: 12 May 2010

Accepted Date: 7 June 2010

Please cite this article as: La Torre M, Ferri M, Giovagnoli MR, Sforza N, Cosenza G, Giarnieri E, Ziparo V. Peritoneal Wash Cytology in Gastric Carcinoma. Prognostic Significance and Therapeutic Consequences, European Journal of Surgical Oncology (2010), doi: 10.1016/j.ejso.2010.06.007

This is a PDF file of an unedited manuscript that has been accepted for publication. As a service to our customers we are providing this early version of the manuscript. The manuscript will undergo copyediting, typesetting, and review of the resulting proof before it is published in its final form. Please note that during the production process errors may be discovered which could affect the content, and all legal disclaimers that apply to the journal pertain. 
Original Article

\section{Peritoneal Wash Cytology in Gastric Carcinoma.}

\section{Prognostic Significance and Therapeutic Consequences}

M. La Torre, M.D.

M. Ferri, M.D.

MR. Giovagnoli, M.D. *

N. Sforza, M.D.

G. Cosenza, M.D.

E. Giarnieri, M.D. *

V. Ziparo, M.D.

Department of Surgery, S. Andrea Hospital, "Sapienza” University of Rome, Rome

* Department of Cytopathology, S. Andrea Hospital, "Sapienza” University of Rome, Rome, Italy

\section{Correspondence:}

Dr. Marco La Torre

Via S. Giovanna Elisabetta 58, 00189 Rome, Italy

Telephone number: 00393402722083

Fax Number: 00390633775322

e-mail: netlat@tiscali.it 


\section{Abstract}

Background and Aims: The prognosis of patients with gastric cancer is poor, even following curative resection, and is related primarily to the extent of disease at presentation. In locally advanced gastric tumors, peritoneal lavage cytology (PLC) is a relevant prognostic factor. The Authors present their results of peritoneal washing cytology, evaluating the prognostic value of this technique, and discussing the clinical impact.

Patients and Methods: From July 2003 to May 2008, results of PLC in 64 patients with histologically proven primary gastric adenocarcinomas were analyzed. At laparotomy the abdomen was irrigated with $200 \mathrm{ml}$ of normal saline, and $\geq 50 \mathrm{ml}$ were aspirated and examined by means of cytology and immunocytopathology.

Results: PLC was positive in 7 cases (11\%). Overall, $86 \%$ of patients with a positive PLC had a pT3/pT4 tumor and 100\% with a positive PLC had a N-positive tumor ( $<<0.001)$; $71 \%$ of patients with a positive PLC had a grade G3/G4 tumor ( $\mathrm{p}=0.001$ ). At a median follow up of 32 months, the cumulative 5-year survival was $28 \%$. The median survival of patients presenting positive PLC (19 months) was significantly lower than that of patients with negative peritoneal cytology (38 months) $(\mathrm{p}=0.0001)$. Multivariate analysis identified cytology as a significant predictor of outcome $(\mathrm{p}=0.018)$.

Conclusions: Results in the present series demonstrated that patients with a positive peritoneal cytology had advanced disease and poor prognosis, thus indicating that patients with locally advanced gastric cancer should undergo staging laparoscopy and PLC examination in order to select those requiring more aggressive treatment.

Future therapeutic strategies should include PLC examination in preoperative staging, in order to select patients for more aggressive treatment.

\section{Mini-abstract}

Positive peritoneal cytology (PC) in gastric cancer is associated with poor prognosis. In locally advanced gastric cancer patients should undergo staging laparoscopy and PC to select those requiring different treatment.

\section{Key Words:}

Peritoneal Wash Cytology; Gastric Carcinoma; intraperitoneal free cancer cells 


\section{Introduction}

Gastric cancer is the third most frequent cause of cancer death in Western countries ${ }^{1}$. Prognosis of these patients is poor, with a cumulative 5-year survival rate of $20 \%$, and this is primarily related to the extent of disease at presentation. Even after R0 resections, approximately $50 \%$ of patients die from recurrent disease within the first 2 years of follow-up ${ }^{2,3}$. The most frequent site of recurrence following R0 resection is the peritoneum ${ }^{4,5}$, probably due to the intraperitoneal presence of free cancer cells shed from the serosal surface of the primary tumor ${ }^{6}$. The majority of patients with intraperitoneal free cancer cells (IFCCs) do not escape postoperative peritoneal recurrence ${ }^{7-9}$. Clinical studies ${ }^{6-8}$ have shown that peritoneal cytology findings are an independent prognostic factor in gastric cancer and, indeed, the Japanese Research Society for Gastric Cancer has now included peritoneal cytology as part of the staging process in gastric cancer ${ }^{10}$.

In this report findings are presented related to a series of 64 patients who underwent laparotomy and PLC for potentially resectable gastric carcinoma, in order to determine the prevalence of positive cytology and to analyze the prognostic significance of IFCCs. 


\section{Materials and Methods}

A review was made of PLC data from 64 consecutive patients (14 female, 50 male, mean age 64.5 years, range 29-84) undergoing laparotomy for gastric carcinoma, between July 2003 and May 2008, at the S. Andrea Hospital - University of Rome.

Overall, 62 patients underwent R0 tumour resection by means of D 1.5 gastrectomy (D1 gastrectomy including lymphectomy of celiac trunk). Two patients were considered not resectable at laparotomy on account of local extension of the tumor, without evidence of peritoneal carcinomatosis.

TNM pathological staging (UICC 1997) revealed 33\% Stage I, 23\% Stage II, 14\% Stage III and $30 \%$ non-metastatic Stage IV tumors. Non-metastatic stage IV patients presented pT4 tumors reaching the mesocolon, duodenum or left hepatic lobe, all of whom submitted to a R0 resection. Tumor grading was as follows: G1 7\%, G2 33\%, G3 51\%, G4 9\%.

Of 64 patients, 27 (42\%) underwent postoperative chemotherapy.

All patients were followed for at least one year or until death. At the time of the present evaluation, the median follow-up time of surviving patients was 32 months (range 12 - 56).

\section{Peritoneal washing}

Upon entering the abdominal cavity, prior to manipulating the tumor, $200 \mathrm{ml}$ of warm normal saline were introduced and manually dispersed in the Douglas cavity, para-colic gutters and in the right and left subphrenic cavity. At least $50 \mathrm{ml}$ of fluid was subsequently recovered, after gentle stirring, from several regions of the abdominal cavity. The fluid was then centrifuged for $5 \mathrm{~min}$ at $1500 \mathrm{rpm}$. The sediment was smeared onto one or more glass slides and stained using the Papanicolau's method. All cytological examinations were performed by experienced cytopathologists. Cytological findings were classified as positive, negative or suspicious. The following cell characteristics were used to determine the presence of malignant cells: presence of aggregate, size, shape, type of cytoplasm, cytoplasmic vacuoli, mainly nuclear abnormalities, nuclear chromatin, nuclearcytoplasmic ratio, mitotic figures, and nucleolar prominence.

When necessary, the glass slide containing the nucleated cell layer was analyzed at immunocytochemistry (ICC) using the CEA antigen antibodies (monoclonal CEA clone 11-7 Dako $^{\circledR}$ ). The glass slide was decolorized using $95 \%$ alcohol and $1 \%$ of chlorhydric acid, and then treated with CEA antibodies. ICC was performed in 20 suspicious cases.

\section{Statistics}

Statistical analyses were performed using MedCalc for Windows, version 10.2.0.0 (MedCalc Software, MariaKerke, Belgium). Differences in distribution were calculated using the chi-square 
test or Fisher's exact test depending on the number of cases in each subgroup. Survival was estimated using Kaplan-Meier's method, and differences were assessed by means of the log-rank test ${ }^{11,12}$. Overall survival was defined as the time interval between surgery and death, regardless of the cause.

$\mathrm{p}<0.1$ was used as the cut-off value for statistical significance in the variable selection in the multivariate modelling in order not to overlook any potentially important predictors. Only those variables significant at univariate analysis were included in the model. Statistical significance remained conventionally defined as $\mathrm{p}<0.05$ in all other cases. 


\section{Results}

Of the 64 tumors, 7 (11\%) showed a positive cytology.

PLC was significantly related to the pathological findings (Table I). Overall $86 \%$ of patients with a positive PLC had a pT3/pT4 tumor and $100 \%$ of the patients with a positive PLC had a N-positive tumor ( $\mathrm{p}<0.001)$; in $71 \%$ of patients with a positive PLC, the tumor grade was G3/G4 $(p=0.001)$. These results indicate that the rate of positive peritoneal wash samples increases proportionally when the tumor invades the deeper layers of the gastric wall or the lymph nodes, and when the tumor has lost differentiation.

At a median follow-up of 32 months, the cumulative 5-year survival rate was $28 \%$. The median overall survival in patients with a positive PLC was significantly lower than that in patients with a negative PLC (19 vs 38 months; p=0.0001) (Figure 1). In the univariate analysis, the extent of the tumor (pT), patient sex and lymph node involvement were also found to be significant predictors of survival, while the tumor grading and age of the patients were not. When these variables were included in a multivariate model, only cytology and the extent of the tumor remained significant independent predictors of survival (Table II).

In a subgroup analysis of pT3/pT4 tumors, patients with a negative PLC lived longer than those with a positive PLC (27 months vs 18 months, $\mathrm{p}=0.06$ ) (Figure 2). Moreover, as far as concerns patients with lymph node involvement, those with a positive PLC had a worse prognosis (19.5 months vs 36 months $\mathrm{p}=0.001$ ) (Figure 3 ). 


\section{Discussion}

Although the surgical treatment (i.e., gastric resection and lymphadenectomy) for gastric carcinoma is well established, patients with advanced disease still have a poor prognosis. Peritoneal metastasis is the most frequent cause of death, with a mean survival of only 6 months following peritoneal recurrence ${ }^{13}$. In patients with serosa involvement, peritoneal recurrence reaches $50 \%$ even if curative resections are performed ${ }^{14,15}$. Peritoneal recurrence develops from peritoneal free cancer cells originating from the primary lesion or metastatic lymph nodes ${ }^{16-18}$. It has been shown that patients with a gastric tumor involving the serosa or the lymph nodes have a high probability of producing peritoneal free cancer cells and developing peritoneal recurrence or carcinomatosis ${ }^{5-10}$. Data in the literature show a significant difference, in terms of survival, between patients with a positive peritoneal cytology and those with negative findings, thus indicating that positive peritoneal cytology is an important prognostic factor. In fact, since 1998, the Japanese Gastric Cancer Association (JGCA) has suggested that the presence of free cancer cells in the peritoneal cavity, should be considered as an independent prognostic marker in patients with gastric cancer ${ }^{10}$, and cytology-positive patients are classified as Stage IV in the gastric cancer classification of the Union International Control Cancer (UICC) ${ }^{19}$.

In the present study, the median overall survival in patients with positive PLC was significantly lower than that in patients with negative PLC (19 vs 38 months; $\mathrm{p}=0.008$ ), and cytology was a significant prognostic marker both at the univariate and multivariate analysis.

PLC is widely accepted as the gold standard for diagnosis of IFCCs. Cytology is easy and safe to perform, it takes approximately 15 min for a cytopathologist to analyze the patient's slides, and the estimated cost for this procedure is $\$ 60^{20}$. The rate of detection of IFCC in the literature ranges from $14 \%-47 \%$, depending upon the cohort of patients studied ${ }^{21}$. When only potentially curative resections are included, the rate of IFCC varies from $4.4 \%-11 \%$, and ranges from $22 \%-30 \%$ in gastric carcinoma involving the serosa ${ }^{22-24}$. In our experience, cytology was positive in $11 \%$ of the entire population studied and in $25 \%$ of patients with a pT3/pT4 tumor.

In agreement with Koga et al. ${ }^{6}$, we found positive peritoneal cytology in 1/30 (2.5\%) pT2 tumors. This finding may depend upon one of 2 conditions, namely: the histological examination of the depth of invasion may not always be performed at a spot where the cancer infiltration is deepest, resulting in $\mathrm{pT}$ downstaging or, the cancer cells could be shed through the lymphatics, from the metastatic lymph nodes or through the lymphatic canals via the omentum ${ }^{20}$. In our series, in fact, the patient with positive cytology and a pT2 tumor presented a N1 status at the final histopathological examination. 
Although IFCCs are detected in a considerable number of gastric cancer patients, the probability of peritoneal recurrence far exceeds the rate of IFCC detected ${ }^{14,15}$. The use of real-time RT-PCR (realtime quantitative reverse transcriptase-polymerase chain reaction) has been reported to increase the sensibility of IFCC detection. In a recent study, CEA mRNA RT-PCR was reported to detect peritoneal free gastric cancer cells at a positive rate $30.0 \%$ higher than cytology alone ${ }^{25}$.

PCR sensitivity is determined primarily by the expression level of the marker gene but also by the corresponding background level of the peritoneal washing. Background level expression requires cut-off strategies especially for samples, such as peritoneal washing, rich in debris and various other different epithelial (frequently reactive mesothelial) and inflammatory cells influencing cDNA quality ${ }^{16}$. Furthermore, the expression of CEA, in disseminated tumor cells, might differ from the tissue resident cells or marker concentration may vary within the tissue due to intratumoral heterogeneity. Therefore, many different variables can be a problem in order to standardize the RTPCR technique for routine diagnostic activity.

The status and viability of free cancer cells considerably influence the potential of the cells for generating metastases. Moreover, not all cancer cells have metastatic potential in the peritoneum. Thus the presence of intact, well preserved cancer cells, as demonstrated by means of the cytological examination, may be of greater prognostic value than free CEA mRNA in gastric cancer patients.

Although general consensus exists regarding the prognostic significance of IFCC in locally advanced gastric cancer, the clinical implications remain unclear since it does not alter the subsequent treatment in the majority of cases. New therapeutic strategies would require peritoneal cytology as part of the preoperative staging. Bryan et al. reported that conventional staging failed to detect incurable disease in 10 patients, representing $11 \%$ of the entire series, inasmuch as 7 of these patients were IFCC positive and could have been more appropriately managed if laparoscopic peritoneal lavage cytology had been used ${ }^{26}$. In a series of 100 patients with locally advanced gastric cancer, Nakagawa et al. ${ }^{27}$ reported that staging laparoscopy with peritoneal lavage cytology allowed upstaging of 44 patients (44\%), thus demonstrating unsuspected IFCC or peritoneal deposits. They also reported that $11 / 18$ patients (61.1\%) with positive cytology who received neoadjuvant chemotherapy, had no free cancer cells at surgery. Patients with positive cytology may also benefit from intraoperative hyperthermic chemotherapy. Several studies have demonstrated the efficacy of this treatment with improvements both in the survival rate and a decrease in the incidence of peritoneal recurrence ${ }^{28-30}$ of patients with gastric cancer and serosal involvement. These data indicate that patients with positive cytology, at staging laparoscopy, could possibly be 
redirected to intraoperative peritoneal hyperthermic chemotherapy or neoadjuvant chemotherapy. Patients presenting progressive disease, during neoadjuvant treatment, may be spared laparotomy. A prospective study is now mandatory in order to assess the efficacy of this alternative treatment in prolonging survival in patients with locally advanced disease.

In conclusion, the results of the present study demonstrate that positive peritoneal cytology, in gastric cancer, is associated with advanced disease and poor prognosis. Future studies should include staging laparoscopy with peritoneal fluid cytology in locally advanced tumors, in order to select those patients with IFCCs for more aggressive therapy. 


\section{References}

1. Parkin DM, Pisani P, Ferlay J. Statistics are given for global patterns of cancer incidence and mortality for males and females in 23 regions of the world. CA Cancer J Clin 1999;49: 33-64.

2. Rajdev L. Treatment Options for Surgically Resectable Gastric Cancer. Curr Treat Options Oncol. 2010 Mar 27. [Epub ahead of print].

3. Lim L, Michael M, Mann GB, Leong T. Adjuvant therapy in gastric cancer. J Clin Oncol. 2005 Sep 1;23(25):6220-32.

4. Yoo CH, Noh SH, Shin DW, Choi SH, Min JS. Recurrence following curative resection for gastric carcinoma. Br J Surg 2000;87:236-42.

5. Benevolo M, Mottolese M, Cosimelli M, Tedesco M, Giannarelli D, Vasselli S, et al. Diagnostic and prognostic value of peritoneal immunocytology in gastric cancer. J Clin Oncol 1998;16:3406-11.

6. Koga S, Kaibara N, Itsuka Y, Kudo H, Kimura A, Hiraoka H. Prognostic significance of intraperitoneal free cancer cells in gastric cancer patients. J Cancer Res Clin Oncol 1984;108:236-8.

7. Ribeiro U Jr, Gama-Rodrigues JJ, Safatle-Ribeiro AV, et al. Prognostic significance of intraperitoneal free cancer cells obtained by laparoscopic peritoneal lavage in patients with gastric cancer. J Gastrointst Surg 1998;2:244-249.

8. Burke EC, Karpeh MS Jr, Conlon KC, Brennan MF. Peritoneal lavage cytology in gastric cancer: an independent predictor of outcome. Ann Surg Oncol 1998;5:411-415.

9. Bentrem D, Wilton A, Mazumdar M, et al. The value of peritoneal cytology as a preoperative predictor in patients with gastric carcinoma undergoing a curative resection. Ann Surg Oncol 2005;12:347-353.

10. Japanese Research Society for Gastric Cancer. Japanese classification of gastric carcinoma. 2nd English ed. Gastric Cancer 1998;1:11-24.

11. Kaplan EL. Meier P. Nonparametric estimation from incomplete observations. J Am Stat Assoc 1958; 53: 457-481.

12. Mantel N. Evaluation of survival data and two new rank order statistics arising in its consideration. Cancer Chemother Rep 1966; 50:163-170.

13. Maekawa S, Saku M, Maehara Y, et al. Surgical treatment for advanced gastric cancer. Hepatogastroenterology 1996;43:178-86. 
14. Moriguchi S, Maehara Y, Korenaga D, et al. Risk factors which predict pattern of recurrence after curative surgery for patients with advanced gastric cancer. Surg Oncol 1992;1:341-6.

15. Iitsuka Y, Shiota S, Matsui T, et al. Relationship between the cytological characteristics of intraperitoneal free cancer cells and the prognosis in patients with gastric cancer. Acta Cytol 1990;34:437-42.

16. Kodera Y, Nakanishi H, Yamamura Y, Shimizu Y, Torii A, Hirai T, Yasui K, Morimoto T, Kato T, Kito T, Tatematsu M. Prognostic value and clinical implications of disseminated cancer cells in the peritoneal cavity detected by reverse tran-scriptase-polymerase chain reaction and cytology. Int J Cancer 1998; 79: 429-433

17. To EM, Chan WY, Chow C, Ng EK, Chung SC. Gastric cancer cell detection in peritoneal washing: cytology versus RT-PCR for CEA transcripts. Diagn Mol Pathol 2003; 12: 88-95.

18. Kojima N, Kunieda K, Matsui K, Kato H, Saji S. Evaluation of carcinoembryonic antigen mRNA in living, necrotic, and apoptotic gastric cancer cells by reverse transcriptasepolymerase chain reaction. Surg Today 2003; 33: 839-846.

19. Sobin LH, Fleming ID. TNM Classification of Malignant Tumors, fifth edition (1997). Union Internationale Contre le Cancer and the American Joint Committee on Cancer. Cancer. 1997 Nov 1;80(9):1803-4.

20. Kodera Y, Yamamura Y, Shimuzu Y, et al. Peritoneal washing cytology: prognostic value of positive findings in patients with gastric carcinoma undergoing a potentially curative resection. J Surg Oncol 1999;72:60-65.

21. Nath J, Moorthy K, Taniere P, M. Hallissey, Alderson D. Peritoneal lavage cytology in patients with oesophagogastric adenocarcinoma. Br J Surg 2008; 95: 721-726.

22. Ribeiro U Jr, Safatle-Ribeiro AV, Zilberstein B, Mucerino D, Yagi OK, Bresciani CC, Jacob CE, Iryia K, Gama-Rodrigues J. Does the intraoperative peritoneal lavage cytology add prognostic information in patients with potentially curative gastric resection? J Gastrointest Surg. 2006;10(2):170-7

23. Suzuki T, Ochiai T, Hayashi, H, et al. Peritoneal lavage cytology findings as prognostic factor for gastric cancer. Semin Surg Oncol1999;17:103-7.

24. Boku T, Nakane Y, Minoura T, et al. Prognostic significance of serosal invasion and free intraperitoneal cancer cells in gastric cancer. Br J Surg 1990;77:436-9.

25. Zhang YS, Xu J, Luo GH, Wang RC, Zhu J, Zhang XY, Nilsson-Ehle P, Xu N. Detection of carcinoembryonic antigen mRNA in peritoneal washes from gastric cancer patients and its clinical significance. World J Gastroenterol. 2006;12(9):1408-11. 
26. Bryan RT, Cruickshank NR, Needham SJ, Moffitt DD, Young JA, Hallissey MT, Fielding JW. Laparoscopic peritoneal lavage in staging gastric and oesophageal cancer. Eur J Surg Oncol. 2001;27(3):291-7.

27. Nakagawa S, Nashimoto A, Yabusaki H. Role of staging laparoscopy with peritoneal lavage cytology in the treatment of locally advanced gastric cancer. Gastric Cancer. 2007;10(1):2934.

28. Zhu ZG, Tang R, Yan M, Chen J, Yang QM, Li C et al. Efficacy and safety of intraoperative peritoneal hyperthermic chemotherapy for advanced gastric cancer patients with serosal invasion. A long term follow-up study. Dig Surg 2006;23: 93-102.

29. Hamazoe R, Maeta M, Kaibara N. Intraperitoneal thermochemotherapy for prevention of peritoneal recurrenceof gastric cancer. Final results of a randomized controlled study. Cancer 1994; 73: 2048-2052.

30. Kim JY, Bae HS. A controlled clinical study of serosa-invasive gastric carcinoma patients who underwent surgery plus intraperitoneal hyperthermo-chemo-perfusion (IHCP). Gastric Cancer 2001; 4: 27-33. 


\section{Figure Legend}

Fig. 1. Overall survival related to cytology, $p=0.0001$

Fig. 2. Survival in patients with a pT3/pT4 tumor according to cytology, $p=0.06$

Fig. 3. Survival in patients with a $\mathrm{pN}+$ tumor according to cytology, $\mathrm{p}=0.001$

\section{Table Legend}

Table I. Correlation between the results of cytology and pathology.

Table II. Multivariate model considering cytology, sex, lymph node involvement $(\mathrm{pN})$ and extent of the tumor (pT). b: coefficient beta; SE: standard error; $\operatorname{Exp}(\mathrm{b})$ : expected beta value; CI: confidence interval. 
Table I.

\begin{tabular}{|c|c|c|c|}
\hline & Cytology positive & Cytology negative & $\mathrm{p}$ \\
\hline No. patients & 7 & 57 & \\
\hline Depth of invasion & & & 0 \\
\hline pT1 & 0 & 9 & \\
\hline pT2 & 1 & 30 & \\
\hline pT3 & 3 & 12 & \\
\hline pT4 & 3 & 6 & \\
\hline Metastatic nodes & & & 0.001 \\
\hline $\mathrm{pN}+$ & 7 & 36 & \\
\hline $\mathrm{pN}-$ & 0 & 21 & \\
\hline Histopathology & & & 0.001 \\
\hline G1/G2 & 2 & 24 & \\
\hline G3/G4 & 5 & 33 & \\
\hline
\end{tabular}


Table II

\begin{tabular}{|l|c|c|c|c|c|}
\hline Covariate & $\mathbf{b}$ & $\mathbf{S E}$ & $\mathbf{E x p}(\mathbf{b})$ & $\mathbf{9 5 \%}$ Cl of $\operatorname{Exp}(\mathbf{b})$ & $\mathbf{p}$ \\
\hline Cytology & 1.2378 & 0.5613 & 3.4482 & 1.1542 to 10.3016 & $\mathbf{0 . 0 2 7 4 2}$ \\
\hline Sex & -0.4615 & 0.6712 & 0.6303 & 0.1703 to 2.3336 & 0.4917 \\
\hline pT & 1.0330 & 0.5867 & 2.8096 & 0.8949 to 8.8208 & $\mathbf{0 . 0 7 8 2 8}$ \\
\hline pN & -0.02576 & 0.6438 & 0.9746 & 0.2777 to 3.4199 & 0.9681 \\
\hline
\end{tabular}




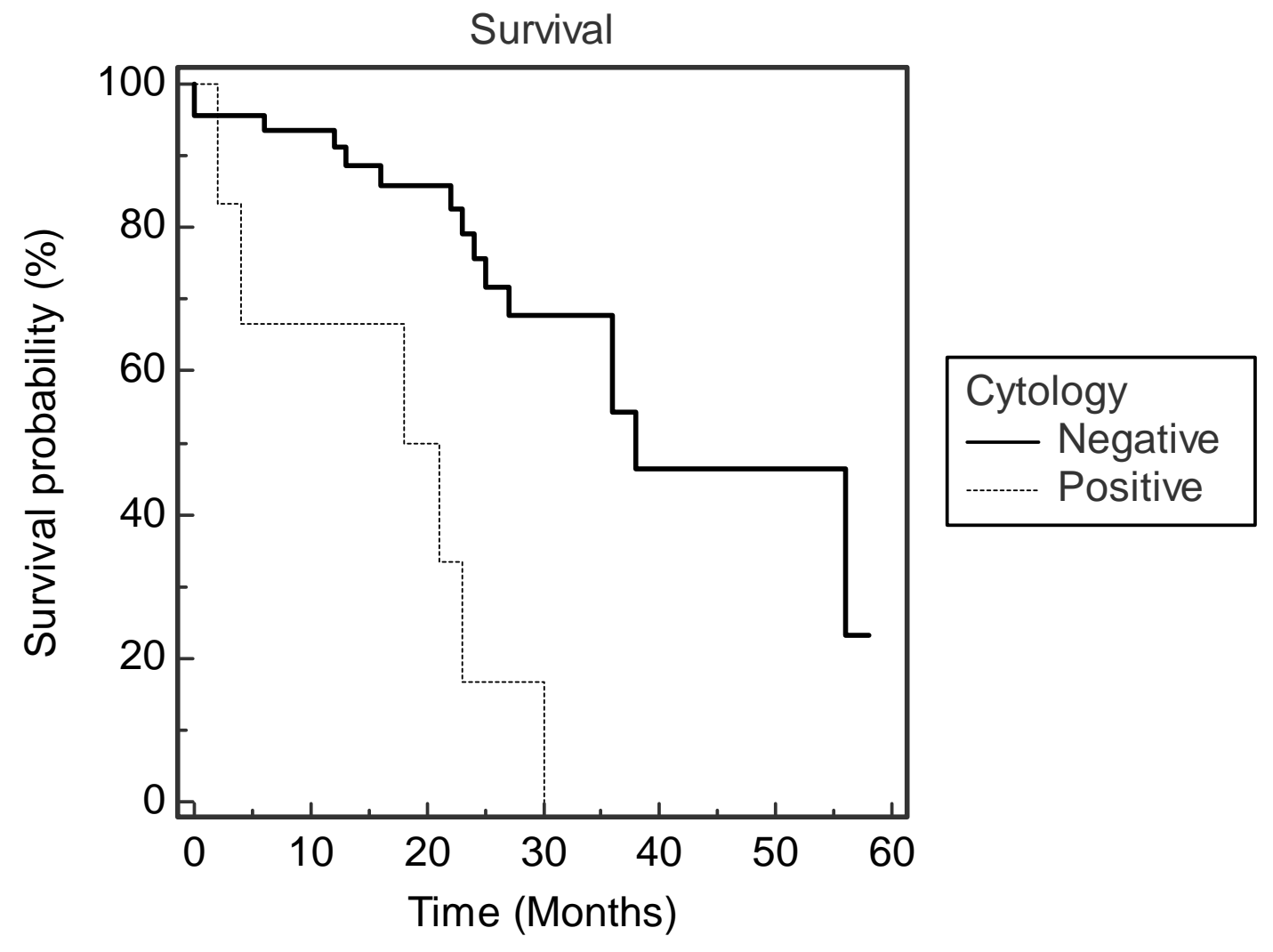

Figure 1. 


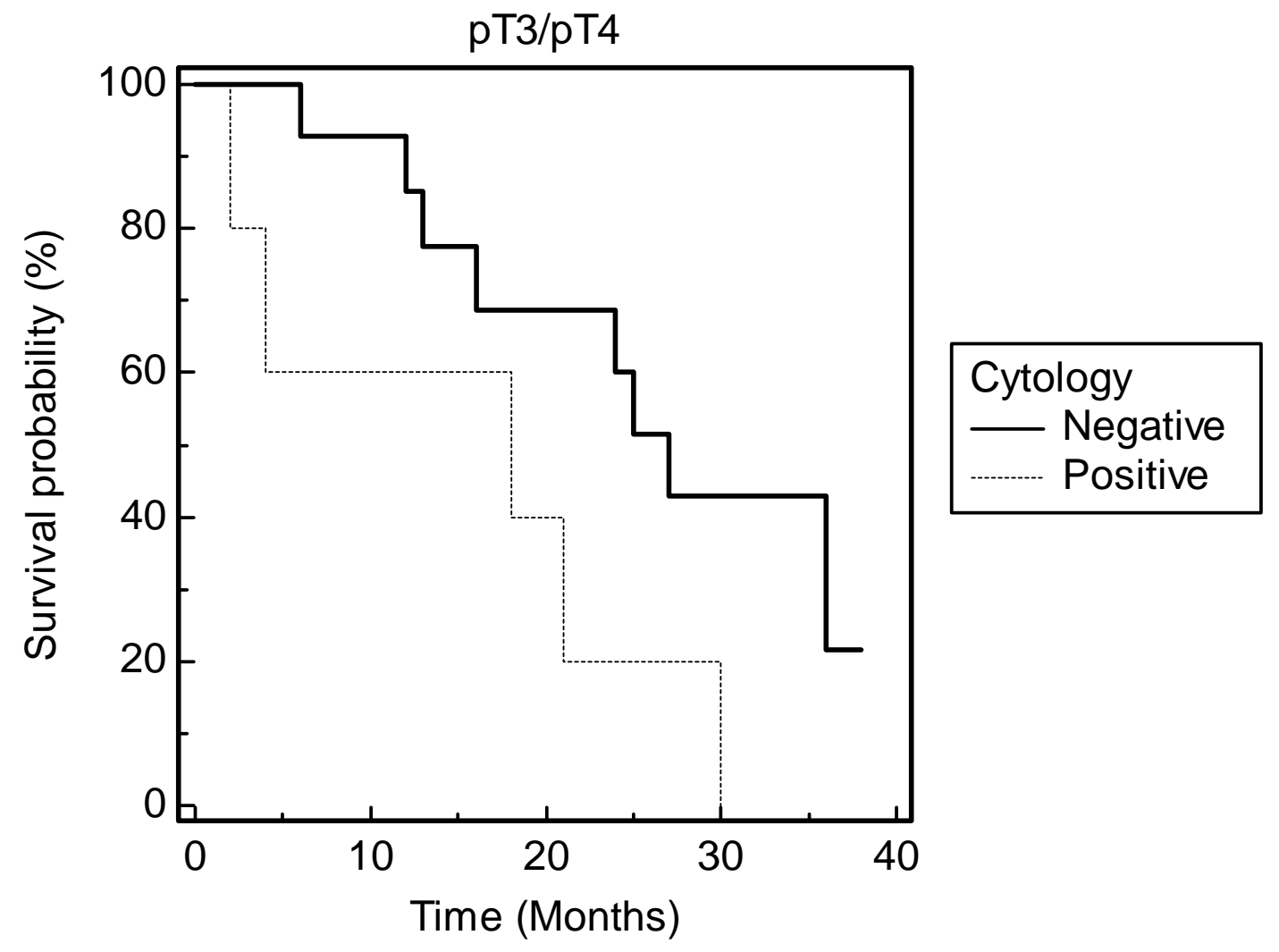

Figure 2. 


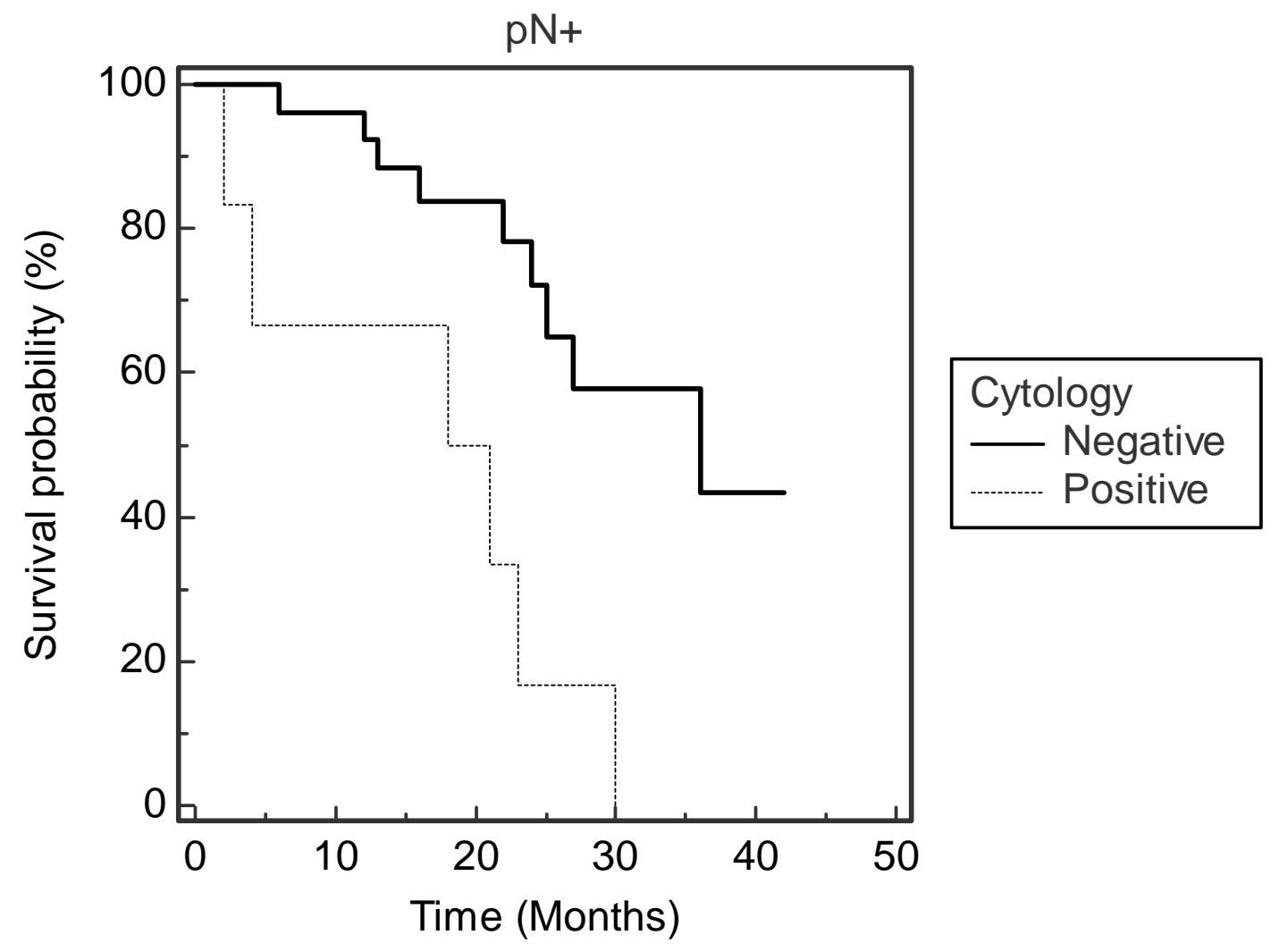

Figure 3. 